The Journal of Nonlinear $\mathbf{S}$ ciences and Applications http://www.tjnsa.com

\title{
ON DECOMPOSITION OF FUZZY A-CONTINUITY
}

\author{
S.JAFARI ${ }^{1}$, K.VISWANATHAN ${ }^{2 *}$, M.RAJAMANI ${ }^{2}$ AND S.KRISHNAPRAKASH ${ }^{2}$ \\ Abstract. In this paper, we introduce and study the notion of fuzzy $C$-sets \\ and fuzzy $C$-continuity. We also prove a mapping $f: X \rightarrow Y$ is fuzzy \\ $A$-continuous if and only if it is both fuzzy semi-continuous and fuzzy $C$-continuous.
}

\section{INTRODUCTION}

In the classical paper [10] of 1965, Zadeh generalized the usual notion of a set by introducing the important and useful notion of fuzzy sets. Since then, this notion has had tremendous effect on both pure and applied mathematics in different respects. Recently El-Naschie has shown in [4] and [5] that the notion of fuzzy topology may be relevant to quantum particle physics in connection with string theory and $\varepsilon^{\infty}$ theory. In 1986, Tong [9] introduced the notion of $A$-sets and $A$-continuous mappings in topological spaces and proved that a mapping is continuous if and only if it is both $\alpha$-continuous and $A$-continuous. In 1990, Ganster [7] established a decomposition of $A$-continuity: A mapping $f: X \rightarrow Y$ is $A$-continuous if and only if it is both semi-continuous and LC-continuous. Erguang and Pengfei [6] introduced the notion of $C$-sets and $C$-continuity and obtained another decomposition of $A$-continuity: A mapping $f: X \rightarrow Y$ is $A$-continuous if and only if it is both semi-continuous and $C$-continuous. Recently, Rajamani and Ambika [8] introduced the notion of fuzzy $A$-sets and fuzzy $A$-continuity and obtained a decomposition of fuzzy continuity.

In this paper, we transform the notions of $C$-set and $C$-continuity to fuzzy topological settings and obtain a decomposition of fuzzy $A$-continuity.

Date: Received: 2 December 2008.

* Corresponding author.

2000 Mathematics Subject Classification. 54A05,54C05.

Key words and phrases. fuzzy A-set, fuzzy C-set, fuzzy A-continuity, fuzzy C-continuity. 


\section{PRELIMINARIES}

Throughout this paper, $X$ and $Y$ denote fuzzy topological spaces $(X, \tau)$ and $(Y, \sigma)$ respectively on which no separation axioms are assumed. Let $\lambda$ be a fuzzy set in a fuzzy topological spaces X. The fuzzy interior of $\lambda$, fuzzy closure of $\lambda$ and fuzzy preclosure of $\lambda$ are denoted by $\operatorname{int}(\lambda), \operatorname{cl}(\lambda)$ and $\operatorname{pcl}(\lambda)$ respectively.

Now, we recall some definitions and results which are used in this paper.

DEFINITION 2.1: A fuzzy set $\lambda$ in a fuzzy topological space $X$ is called

(1) fuzzy semi-open [1] if $\lambda \leq \operatorname{cl}(\operatorname{int}(\lambda))$;

(2) fuzzy pre-open [2] if $\lambda \leq \operatorname{int}(\operatorname{cl}(\lambda))$;

(3) fuzzy regular-open [1] if $\lambda=\operatorname{int}(\operatorname{cl}(\lambda))$.

The complements of the above mentioned fuzzy open sets are called their respective fuzzy closed sets.

DEFINITION 2.2: A fuzzy set $\lambda$ in a fuzzy topological space $X$ is called a fuzzy $A$-set [6] if $\lambda=\alpha \wedge \beta$, where $\alpha$ is a fuzzy open set and $\beta$ is a fuzzy regular closed set.

DEFINITION 2.3: A map $f: X \rightarrow Y$ is said to be

(1) fuzzy continuous [3] if $f^{-1}(\mu)$ is fuzzy open in $X$, for every fuzzy open set $\mu$ in $Y$;

(2) fuzzy semi-continuous [1] if $f^{-1}(\mu)$ is fuzzy semi-open in $X$, for every fuzzy open set $\mu$ in $Y$;

(3) fuzzy pre-continuous [2] if $f^{-1}(\mu)$ is fuzzy pre-open in $X$, for every fuzzy open set $\mu$ in $Y$;

The collection of all fuzzy $C$-sets and fuzzy semi-open sets in $\mathrm{X}$ will be denoted by $\mathrm{FC}(\mathrm{X}, \tau)$ and $\mathrm{FSO}(\mathrm{X}, \tau)$ respectively.

\section{FUZZY $C$-SETS}

DEFINITION 3.1: A fuzzy set $\lambda$ in a fuzzy topological space $X$ is called a fuzzy $C$-set if $\lambda=\alpha \wedge \beta$, where $\alpha$ is fuzzy open and $\beta$ is fuzzy pre-closed in $X$.

PROPOSITION 3.2: Every fuzzy $A$-set is a fuzzy $C$-set.

REMARK 3.3: The converse of the Proposition 3.2. need not be true as seen from the following example.

EXAMPLE 3.4: Let $X=\{a, b, c\}$, Define $\alpha_{1}, \alpha_{2}, \alpha_{3}: X \rightarrow[0,1]$ by

$\alpha_{1}(\mathrm{a})=0.3 \quad \alpha_{2}(\mathrm{a})=0.4 \quad \alpha_{3}(\mathrm{a})=0.7$

$\alpha_{1}(\mathrm{~b})=0.4 \quad \alpha_{2}(\mathrm{~b})=0.5 \quad \alpha_{3}(\mathrm{~b})=0.6$

$\alpha_{1}(\mathrm{c})=0.4 \quad \alpha_{2}(\mathrm{c})=0.5 \quad \alpha_{3}(\mathrm{c})=0.6$

Let $\tau=\left\{0,1, \alpha_{1}, \alpha_{2}\right\}$. Then $(X, \tau)$ is a fuzzy topological space. Now, $\alpha_{3}$ is a 
fuzzy $C$-set but not a fuzzy $A$-set.

REMARK 3.5: The concepts of fuzzy $C$-sets and fuzzy semi-open sets are independent as shown by the following examples.

EXAMPLE 3.6: Let $X=\{a, b, c\}$, Define $\alpha_{1}, \alpha_{2}, \alpha_{3}: X \rightarrow[0,1]$ by $\alpha_{1}(\mathrm{a})=0.2 \quad \alpha_{2}(\mathrm{a})=0.3 \quad \alpha_{3}(\mathrm{a})=0.3$

$\alpha_{1}(\mathrm{~b})=0.3 \quad \alpha_{2}(\mathrm{~b})=0.3 \quad \alpha_{3}(\mathrm{~b})=0.3$

$\alpha_{1}(\mathrm{c})=0.3 \quad \alpha_{2}(\mathrm{c})=0.4 \quad \alpha_{3}(\mathrm{c})=0.3$

Let $\tau=\left\{0,1, \alpha_{1}, \alpha_{2}\right\}$. Then $(X, \tau)$ is a fuzzy topological space. Now, $\alpha_{3}$ is a fuzzy semi-open set but not a fuzzy $C$-set.

EXAMPLE 3.7: Let $X=\{a, b, c\}$, Define $\alpha_{1}, \alpha_{2}, \alpha_{3}: X \rightarrow[0,1]$ by

$\alpha_{1}(\mathrm{a})=0.4 \quad \alpha_{2}(\mathrm{a})=0.6 \quad \alpha_{3}(\mathrm{a})=0.5$

$\alpha_{1}(\mathrm{~b})=0.5 \quad \alpha_{2}(\mathrm{~b})=0.7 \quad \alpha_{3}(\mathrm{~b})=0.6$

$\alpha_{1}(\mathrm{c})=0.6 \quad \alpha_{2}(\mathrm{c})=0.8 \quad \alpha_{3}(\mathrm{c})=0.7$

Let $\tau=\left\{0,1, \alpha_{1}, \alpha_{2}\right\}$. Then $(X, \tau)$ is a fuzzy topological space. Now, $\alpha_{3}$ is a fuzzy $C$-set but not a fuzzy semi-open set.

LEMMA 3.8: $\quad$ Let $\alpha$ be a fuzzy set in a fuzzy topological space $X$. Then $\alpha \in F C(X, \tau)$ if and only if $\alpha=\lambda \wedge \operatorname{pcl}(\alpha)$ for some fuzzy open set $\lambda$.

Proof: Let $\alpha \in F C(X, \tau)$. Then $\alpha=\lambda \wedge \mu$ where $\lambda$ is fuzzy open and $\mu$ is fuzzy pre-closed. Now, $\alpha \leq \lambda$ and $\alpha \leq \mu$, we have $\operatorname{pcl}(\alpha) \leq \operatorname{pcl}(\mu)=\mu$, since $\mu$ is fuzzy pre-closed in X. Thus $p c l(\alpha) \leq \mu$. Therefore $\lambda \wedge p c l(\alpha) \leq(\lambda \wedge \mu)=\alpha \leq \lambda \wedge p \operatorname{pl}(\alpha)$. (i.e.,) $\lambda \wedge p c l(\alpha)=\alpha$.

Converse part is obvious.

THEOREM 3.9: Let $\alpha$ be a fuzzy set in a fuzzy topological space X. Then $\alpha=$ $\lambda \wedge \operatorname{cl}(\operatorname{int}(\alpha))$ for some fuzzy open set $\lambda$ if and only if $\alpha \in F C(X, \tau) \wedge F S O(X, \tau)$.

Proof: Let $\alpha=\lambda \wedge \operatorname{cl}(\operatorname{int}(\alpha))$ for some fuzzy open set $\lambda$ in $\mathrm{X}$. Then $\alpha \leq \operatorname{cl}(\operatorname{int}(\alpha))$. So $\alpha$ is fuzzy semi open in $\mathrm{X}$. Let $\beta=\operatorname{cl}(\operatorname{int}(\alpha))$, then $\beta$ is fuzzy regular closed. Since every fuzzy regular closed set is fuzzy pre-closed, $\beta$ is fuzzy pre-closed which implies $\alpha$ is fuzzy $C$-set. Thus $\alpha \in F C(X, \tau) \wedge F S O(X, \tau)$.

Conversely, let $\alpha \in F C(X, \tau) \wedge F S O(X, \tau)$. Then $\alpha \in F C(X, \tau)$ and $\alpha \in$ $F S O(X, \tau)$. Since $\alpha \in F C(X, \tau), \alpha=\lambda \wedge \operatorname{pcl}(\alpha)$, using Lemma 3.8. Thus $\alpha=\lambda \wedge \operatorname{cl}(\operatorname{int}(\alpha))$ for some fuzzy open set $\lambda$.

\section{DECOMPOSITION OF FUZZY $A$-CONTINUITY}

DEFINITION 4.1: A mapping $f: X \rightarrow Y$ is called fuzzy $A$-continuous if $f^{-1}(\mu)$ is a fuzzy $A-$ set in $X$, for every fuzzy open set $\mu$ in $Y$. 
DEFINITION 4.2: A mapping $f: X \rightarrow Y$ is called fuzzy $C$-continuous if $f^{-1}(\mu)$ is a fuzzy $C$-set in $X$, for every fuzzy open set $\mu$ in $Y$.

PROPOSITION 4.3: Every fuzzy $A$-continuous function is fuzzy $C$-continuous.

REMARK 4.4: The converse of Proposition 4.3 need not be true as shown by the following example.

EXAMPLE 4.5: Let $X=\{a, b, c\}, Y=\{x, y, z\}$ and $\alpha_{1}, \alpha_{2}$ and $\alpha_{3}$ are fuzzy sets defined as follows :
$\alpha_{1}(\mathrm{a})=0.3$
$\alpha_{2}(\mathrm{a})=0.4$
$\alpha_{3}(\mathrm{a})=0.7$
$\alpha_{1}(\mathrm{~b})=0.4$
$\alpha_{2}(\mathrm{~b})=0.5$
$\alpha_{3}(\mathrm{~b})=0.6$
$\alpha_{1}(\mathrm{c})=0.4$
$\alpha_{2}(\mathrm{c})=0.5$
$\alpha_{3}(\mathrm{c})=0.6$

Let $\tau_{1}=\left\{0,1, \alpha_{1}, \alpha_{2}\right\}, \tau_{2}=\left\{0,1, \alpha_{3}\right\}$. Then the mapping $f:\left(X, \tau_{1}\right) \rightarrow\left(Y, \tau_{2}\right)$ defined by $\mathrm{f}(\mathrm{a})=\mathrm{x}, \mathrm{f}(\mathrm{b})=\mathrm{y}$ and $\mathrm{f}(\mathrm{c})=\mathrm{z}$ is fuzzy $C$-continuous but not fuzzy $A$-continuous.

REMARK 4.6: The concepts of fuzzy $C$-continuity and fuzzy semi-continuity are independent as shown by the following examples.

THEOREM 4.7: Let $X=\{a, b, c\}, Y=\{x, y, z\}$ and $\alpha_{1}, \alpha_{2}$ and $\alpha_{3}$ are fuzzy sets defined as follows :

$\alpha_{1}(\mathrm{a})=0.2 \quad \alpha_{2}(\mathrm{a})=0.3 \quad \alpha_{3}(\mathrm{a})=0.3$

$\alpha_{1}(\mathrm{~b})=0.3 \quad \alpha_{2}(\mathrm{~b})=0.3 \quad \alpha_{3}(\mathrm{~b})=0.3$

$\alpha_{1}(\mathrm{c})=0.3 \quad \alpha_{2}(\mathrm{c})=0.4 \quad \alpha_{3}(\mathrm{c})=0.3$

Let $\tau_{1}=\left\{0,1, \alpha_{1}, \alpha_{2}\right\}, \tau_{2}=\left\{0,1, \alpha_{3}\right\}$. Then the mapping $f:\left(X, \tau_{1}\right) \rightarrow\left(Y, \tau_{2}\right)$ defined by $\mathrm{f}(\mathrm{a})=\mathrm{x}, \mathrm{f}(\mathrm{b})=\mathrm{y}$ and $\mathrm{f}(\mathrm{c})=\mathrm{z}$ is fuzzy semi-continuous but not fuzzy $C$-continuous.

EXAMPLE 4.8: Let $X=\{a, b, c\}, Y=\{x, y, z\}$ and $\alpha_{1}, \alpha_{2}$ and $\alpha_{3}$ are fuzzy sets defined as follows :

$\begin{array}{lll}\alpha_{1}(\mathrm{a})=0.4 & \alpha_{2}(\mathrm{a})=0.6 & \alpha_{3}(\mathrm{a})=0.5 \\ \alpha_{1}(\mathrm{~b})=0.5 & \alpha_{2}(\mathrm{~b})=0.7 & \alpha_{3}(\mathrm{~b})=0.6 \\ \alpha_{1}(\mathrm{c})=0.6 & \alpha_{2}(\mathrm{c})=0.8 & \alpha_{3}(\mathrm{c})=0.7\end{array}$

Let $\tau_{1}=\left\{0,1, \alpha_{1}, \alpha_{2}\right\}, \tau_{2}=\left\{0,1, \alpha_{3}\right\}$. Then the mapping $f:\left(X, \tau_{1}\right) \rightarrow\left(Y, \tau_{2}\right)$ defined by $\mathrm{f}(\mathrm{a})=\mathrm{x}, \mathrm{f}(\mathrm{b})=\mathrm{y}$ and $\mathrm{f}(\mathrm{c})=\mathrm{z}$ is fuzzy $C$-continuous but not fuzzy semi-continuous.

THEOREM 4.9: A mapping $f: X \rightarrow Y$ is fuzzy $A$-continuous if and only if it is both fuzzy semi-continuous and fuzzy $C$-continuous.

Proof: Follows from Theorem 3.9. 


\section{REFERENCES}

1. Azad, K.K., On fuzzy semi-continuity, fuzzy almost continuity, J. Math. Anal. Appl., 87(1981), 14-32.

2. Bin Shahana, A.S., On fuzzy strong semi-continuity and fuzzy pre-continuity, Fuzzy sets and system, 44(1991), 303-308.

3. Chang, C.L. Fuzzy topological spaces, J. Math. Anal. Appl.,24,(1968),182-190.

4. El-Naschie, M. S. On the uncertanity of cantorian geometry and the two-slit experiment, Chaos, Solitons and fractals $9(3)(1998), 517-529$.

5. El-Naschie, M. S., On the certification of heterotic strings, M theory and $\varepsilon^{\infty}$ theory, chaos, Solitons and fractals (2000), 2397-2408

6. Erguang, Y. and Pengfei, Y., On decomposition of A- continuity, Acta Math. Hunger., 110(4)(2006),309-313.

7. Ganster, M. and Reilly, I.L., A decomposition of continuity, Acta Math. Hunger., 56(1990),299-301.

8. Rajamani, M. and Ambika, M., Another decomposition of fuzzy continuity in fuzzy topological spaces, Proc. Of Annual Conference of KMA and National Seminar on Fuzzy Mathematics and Applications, Payyanur College, Payyanur, Jan 8-10, (2004) ,41-48.

9. Tong, J., A decomposition of fuzzy continuity, Fuzzy Math, 7(1987), 97-98.

10. Zadeh, L. A., Fuzzy sets, Inform. and Control 8(1965), 338-353.

1 College of Vestsjaelland South

HERRESTRADE 11

4200 SLAGELSE

DENMARK.

E-mail address: jafari@stofanet.dk

2 Post Graduate and Research Department of Mathematics

N G M College

PollaCHI-642 001

TAMILNADU, INDIA.

E-mail address: visu_ngm@yahoomail.com 